\title{
The deteriorating status of African rhinos
}

\author{
David Western and Lucy Vigne
}

\begin{abstract}
Rhinos have given conservationists cause for concern for many decades, and there have been regular reports in Oryx of their deteriorating status in several countries. Now the authors, former Chairman and Executive Officer, respectively, of the IUCN/SSC African Elephant and Rhino Specialist Group, give an up-to-date account of rhinos in Africa, their numbers, distribution, and descriptions of areas where they are particularly vulnerable, as well as those where conservation action is having a positive effect.
\end{abstract}

African rhinos have long been on a steady path to extinction. Bryden (1897) reported that the once common southern white rhino Ceratotherium simum simum was all but extinct by 1894 . More than two decades ago, Ritchie (1963) cautioned that black rhinos Diceros bicomis were disappearing as rapidly and surely as had Asian rhinos, and that no animal in the world was so greatly in need of skilled conservation. Although the evidence was there to the contrary, Ritchie claimed that evolutionary flexibility, not poaching, was driving rhinos to extinction. Other authorities saw hunting and poaching as the immediate threat (Grzimek, 1964; Simon, 1962). As the price of rhino horn rose from around $\$ 20$ per $\mathrm{kg}$ in the late 1960 s to $\$ 80$ per kg by 1976 (Parker and Martin 1979), poaching increased so rapidly as to leave no doubt of its impact and the impending extermination of rhinos. Martin's $(1979,1983)$ comprehensive Asian trade survey connected the poaching losses to an increasing demand for rhino horn as a pharmaceutical product in the Far East and for Arab dagger handles in the Near East. The rapid decline of many populations was well documented through this period (Western and Sindiyo, 1972; Hillman, 1980; Borner, Deteriorating status of African rhinos
1981) and widely publicized, leading to an international conservation rescue plan (Hillman, 1981; IUCN, 1982).

Although rhino numbers had previously been estimated for many populations and regions (Sidney, 1965; Goddard, 1967), Hillman (1981) provided the first scientific continental estimates for African rhinos, when she estimated 14,00015,000 black rhinos, 3000 southern white rhinos and fewer than 1000 northern white rhinos Ceratotherium simum cottoni. This report, undertaken on behalf of the IUCN/SSC African Elephant and Rhino Specialist Group (AERSG) and the New York Zoological Society, updates Hillman's surveys, reviews the status of all subspecies of black and white rhinos, and considers the conservation implications.

\section{Questionnaire surveys}

Questionnaire surveys were sent out to individuals and organizations in all countries having rhinos, asking for an update on the numbers and distributions published by Hillman (1981). Estimates and range maps, made for each population in every country, were based on data and responses from 39 individuals. For black rhino estimates, 56 per cent were based on aerial or ground counts, 35 per cent on reconnaissance surveys and 9 per cent on informed guesses. Corresponding categories for the southern white rhino were 92 per cent, 4 per cent and 4 per cent, and for the northern white rhino, 55 per cent, 2 per cent and 43 per cent, respectively.

To estimate the numbers of each race of black rhino, we used the classification and range distributions given by Groves (1967). The northern 
and southern white rhino, being allopatric, are easy to enumerate separately.

\section{Rhino numbers in 1984}

The black rhino total has declined sharply from a 1980 estimate of $14,000-15,000$ to around 9000 in 1984 (Table 1). The approximate 40 per cent continental decline is predominantly due to losses in the Central African Republic (CAR), Zambia and Tanzania. The reduction in Kenya's estimate reflects more an improvement in counts than true poaching losses. Severe poaching, often organized by heavily armed Sudanese gangs who earlier destroyed their own rhinos (Hillman, 1983), is known to have knocked out large numbers of CAR animals in recent years (Ruggiero, 1984). Rhino poaching losses in Tanzania are documented in the north (Borner, $1981)$ and Ruaha National Park in the south (M. Borner, pers. comm.), and may be building up rapidly in Selous Game Reserve, which has 3000 rhinos-a third of Africa's total. Most Zambian poaching losses occurred in Luangwa Valley National Park. Black rhinos have become extinct

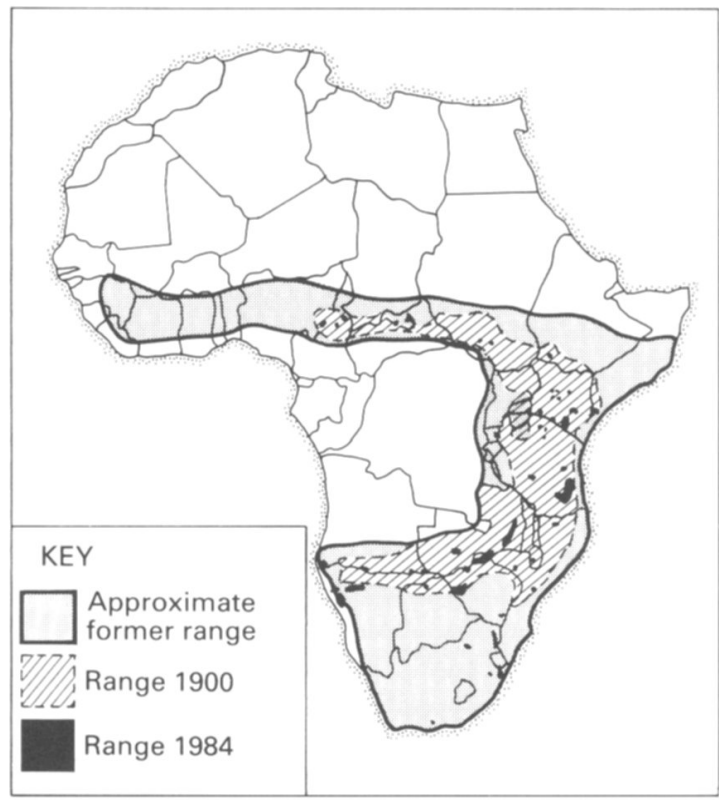

Figure 1. Black rhino range.

in Uganda in the last four years, and nearly so in Chad, Ethiopia, Botswana, Rwanda, Malawi and

Table 1. Estimated number of black and white rhinos in Africa by country

\begin{tabular}{|c|c|c|c|c|c|c|c|}
\hline \multirow[b]{3}{*}{ Country } & \multicolumn{2}{|c|}{ Black rhino } & \multirow{3}{*}{$\begin{array}{l}\% \text { of total } \\
\text { rhino } \\
\text { population } \\
1984\end{array}$} & \multicolumn{4}{|c|}{ White rhino } \\
\hline & \multirow[b]{2}{*}{1980} & \multirow[b]{2}{*}{1984} & & \multicolumn{2}{|c|}{1980} & \multicolumn{2}{|c|}{1984} \\
\hline & & & & Southern & Northern & Southem & Northern \\
\hline Tanzania & 3795 & 3130 & 35.5 & - & - & - & - \\
\hline Zimbabwe & 1400 & 1680 & 19.0 & 180 & - & 200 & - \\
\hline Zambia & 2750 & 1650 & 18.7 & 5 & - & 10 & - \\
\hline S. Africa & 630 & 640 & 7.3 & 2500 & - & 3330 & - \\
\hline Kenya & 1500 & 550 & 6.3 & 25 & - & 30 & - \\
\hline Namibia & 300 & 400 & 4.6 & 150 & - & 70 & - \\
\hline CAR & 3000 & 170 & 1.9 & - & 20 & - & 1 \\
\hline Mozambique & 250 & 130 & 1.5 & 30 & - & 20 & 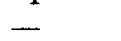 \\
\hline Cameroon & 110 & 110 & 1.2 & - & - & - & - \\
\hline Sudan & 300 & 100 & 1.2 & - & 400 & - & 10 \\
\hline Somalia & 300 & 90 & 1.1 & - & - & - & - \\
\hline Angola & 300 & 90 & 1.0 & - & - & - & - \\
\hline Malawi & 40 & 20 & 0.2 & - & - & - & - \\
\hline Rwanda & 30 & 15 & 0.2 & - & - & - & - \\
\hline Botswana & 30 & 10 & 0.1 & 70 & - & 200 & - \\
\hline Ethiopia & 20 & 10 & 0.1 & - & - & - & - \\
\hline Chad & 25 & 5 & 0.1 & - & - & - & - \\
\hline Uganda & 5 & - & & - & 1 & - & 1 \\
\hline Zaire & - & - & & - & 400 & - & 15 \\
\hline Swaziland & - & - & & 60 & - & 60 & - \\
\hline Total & 14,785 & 8800 & & 3020 & 821 & 3920 & 28 \\
\hline
\end{tabular}


Table 2. Estimated number of black rhinos for each subspecies

\begin{tabular}{llrrr}
\hline Subspecies & Range & 1980 & 1984 & $\%$ change \\
\hline D. minor & Kenya to South Africa and Namibia & 6895 & 5840 & $15 \downarrow$ \\
D. michaeli & Kenya and Tanzania & 3480 & 1975 & $43 \downarrow$ \\
D. bicornis & South Africa & 300 & 400 & $33 \uparrow$ \\
D. longipes & Mostly in CAR & 3135 & 285 & $91 \downarrow$ \\
D. ladoensis & Mostly northern Kenya and Sudan & 345 & 110 & $68 \downarrow$ \\
D. chobiensis & Mostly Angola & 330 & 100 & $70 \downarrow$ \\
D. brucii & Mostly Ethiopia and Somalia & 300 & 90 & $70 \downarrow$ \\
Total & & 14,785 & 8800 & $40 \downarrow$ \\
\hline
\end{tabular}

possibly Somalia; Sudan and Angola have lost two-thirds and Mozambique one-half. The only countries reporting more rhinos now than in 1984 are Zimbabwe, Namibia and South Africa.

The extensive and relatively continuous black rhino range of historical times has contracted rapidly since the turn of the century (Figure 1) to numerous isolated, diminutive populations. More than 50 per cent of all rhino populations now number fewer than 20 animals, and the fragmentation in the last four years has been very rapid (Figure 2).

Losses among the various black rhino races have varied greatly since 1980 (Table 2). Longipes, ladoensis, chobiensis and brucii are heavily poached and will become extinct in the next few years unless present trends are soon reversed. Michaeli has declined, but still numbers nearly 2000 and, being well protected on some private ranches in Kenya, is vulnerable, but not endangered. Minor, which is the most common and widespread race, is relatively secure, while bicomis is on the increase in South Africa and is safe.

Southern white rhinos have continued to increase since the turnaround point in the 1930s when the population slumped to fewer than 100 animals,

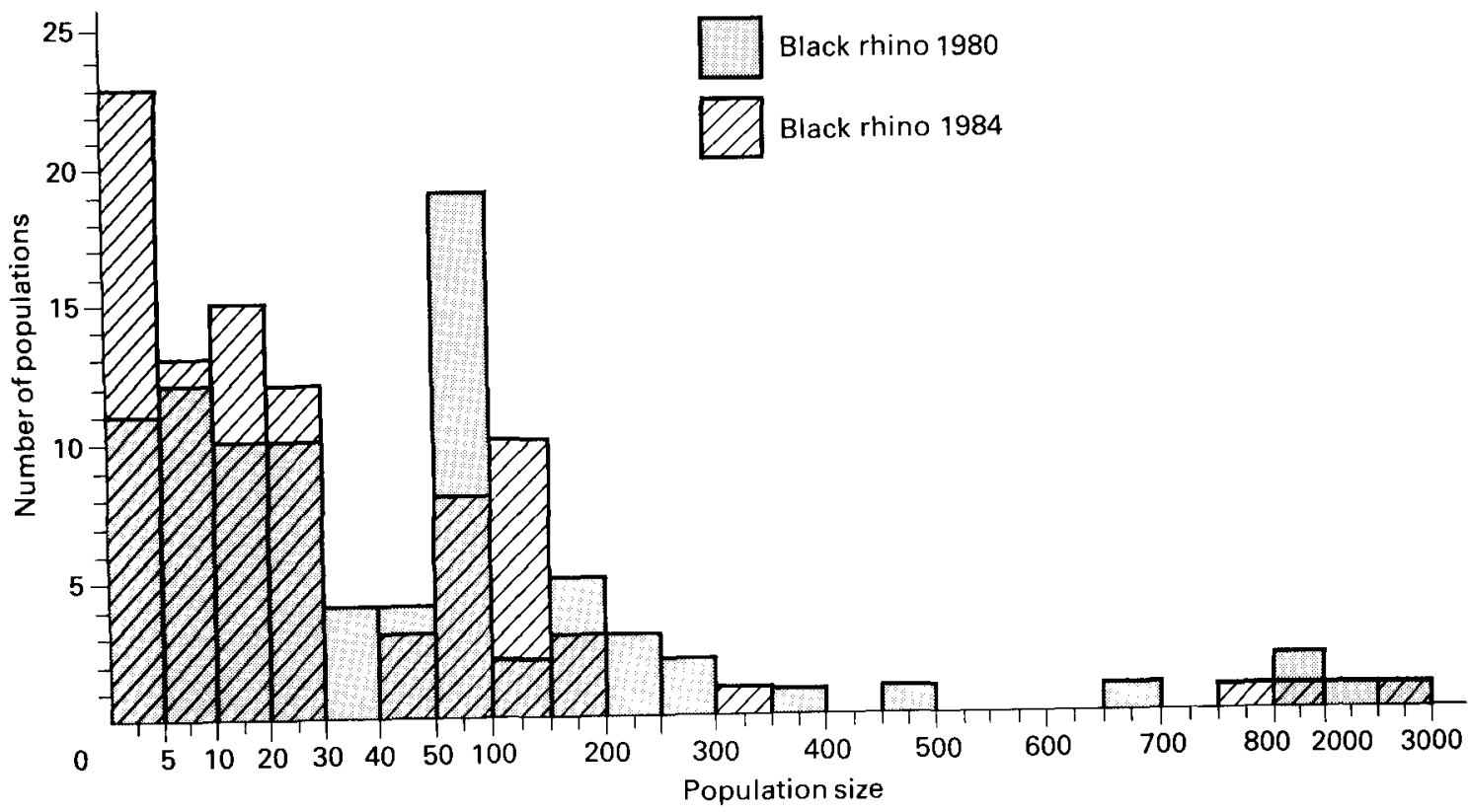

Figure 2. Black rhino populations showing the increase in frequency of small populations. 
centred on Umfolozi (Owen-Smith, 1981). The 6 per cent annual increase since 1980 is mainly due to a continuing near 10 per cent increase in South Africa (Owen-Smith, 1981), rather than large increases in all other countries to which they have been introduced over the last few decades. The populations have increased in Zimbabwe, Botswana, Kenya and Zambia, but have decreased in Namibia and Mozambique (Table 1).

The status of the northern white rhino, which has declined more than 95 per cent in the last four years, is exceedingly precarious. The race is now effectively extinct in Uganda, CAR, almost certainly in Sudan, and only 13 are positively known to survive in Garamba National Park in Zaire (Mackie, 1984). Poaching is entirely responsible for the losses (Hillman et al., in press).

\section{Regions for concern}

Four geographic regions are important in considering rhino conservation. The northern region, which covers 39 per cent of their former range, has only some 500 black rhinos, 5 per cent of Africa's total, distributed in Cameroon, CAR, Chad, Sudan, Rwanda, Uganda, Ethiopia and Somalia, and less than 1 per cent of all white rhinos. Both species have declined by 90 per cent or more in the last five years. Here too, three of the seven recognized black rhino races and one of the two recognized white rhino races are likely to become extinct in the wild in the next few years.

The central geographic region, almost as vulnerable, includes Angola, Botswana, Malawi and Mozambique, which covers 13 per cent of the black rhino's former range and currently has only around 250 , or 2 per cent of Africa's rhinos. Here, the black rhino decline has been of the order of 60 per cent in the last five years, and the race chobiensis is likely to become extinct in the next few years.

The eastern geographic region, including Kenya, Tanzania and Zambia, which covers 23 per cent of the rhinos' former range, has 60 per cent of Africa's black rhinos and has lost perhaps onethird in the last five years. The endemic subspecies michaeli is relatively safe for the moment.

The southern region, South Africa, Zimbabwe and Namibia, covers 25 per cent of the black 218 rhino's former range, has around 2700 animals, or 30 per cent of Africa's total, and shows a 10 per cent increase over the last five years. The endemic subspecies, bicomis, is on the increase, and, with the exception of Namibia, white rhinos are increasing rapidly (Table 1 ).

Most northern and central countries, though relatively sparsely populated, are poor and have rebel activity, or are affected by that of neighbouring states, and in virtually all, firearms, including automatic weapons, are in widespread use (Douglas-Hamilton, 1983). Commercial animals, particularly elephants and rhinos, are easily shot and traded, even in the remotest areas. It is difficult to imagine that the status of the remaining 750 rhinos in either region will improve, for even where the political will exists, as in Ethiopia, the logistical difficulties and cost of protecting a few widely scattered animals against heavily armed and determined poaching gangs are simply too formidable.

In stark contrast, the situation in South Africa and Zimbabwe shows that both black and white rhinos can be rehabilitated very successfully once poaching is curtailed. The story of the white rhino's recovery is one of the triumphs of conservation. Capture, translocation and rehabilitation work is leading to an equally impressive black rhino recovery in southern Africa (Anon., 1984). However, while illustrative of what can be achieved with sufficient funds and management skill, it is unrealistic to expect that many African states can afford the necessary resources.

This does not apply to Kenya, Tanzania and Zambia, the most important black rhino regions. The recognition these three countries give to wildlife, its importance in their lucrative tourist and hunting industries, tight arms control, and relatively good conservation departments, offer us the best chance to save sizeable natural populations. Funding from the three governments, and from international conservation bodies, has slowed poaching in areas such as Luangwa Valley in Zambia, Ngorongoro in Tanzania and Aberdares in Kenya. The East African populations are, because of their size and accessibility, the only substantial source of rhino horn and, therefore, will remain highly vulnerable. The fate of black rhinos in this region will Oryx Vol 19 No 4 
determine whether the species continues to decline sharply, or stabilizes. More particularly, the fate of three populations-in Luangwa, Selous and the Kenya highlands-which between them constitute over half of Africa's total, will greatly decide the future of black rhinos outside southern Africa and zoos.

\section{The problems with fragmentation}

We caution that the status of the black rhino depends as much, perhaps more, on its continued fragmentation as on absolute numbers. Population fragmentation poses both short-term conservation problems and long-term biological hazards. As most rhinos are now in small isolated populations (Figure 2), it is difficult and costly to protect them (Western, 1982). Once numbers drop as low as 20 animals or fewer, the per capita protection costs are exceedingly high, and rarely justifiable to understaffed and underfinanced wildlife departments. The biological problems are equally, if less immediately, worrying. In small populations, sex ratio and age structure can be so skewed as to cause a drop in birth rate and recovery potential (Goodman, 1981). Inbreeding depression is also likely to dampen recovery, reduce genetic heterogeneity and consequently resilience and adaptability (Soulé, 1981), especially in species as ubiquitous as the black rhino, which is unlikely to have previously experienced a severe genetic bottleneck, and therefore to have acquired any strong inbreeding tolerance.

\section{Towards a more hopeful future}

We conclude that the status of rhinos is critical, but not irretrievable. On the one hand, both species are likely to be more or less exterminated in their northern and central range; on the other, intensive surveillance and management are leading to their rapid recovery in southern Africa. Black rhinos in eastern Africa are poised between the two extremes. Closer surveillance and active management, which will require considerably more governmental planning and international support, could secure as good a protection for eastern as for southern African rhinos. The best hope of this happening is for each country to formulate national rhino conservation plans, much as Kenya is now doing. This involves Deteriorating status of African rhinos

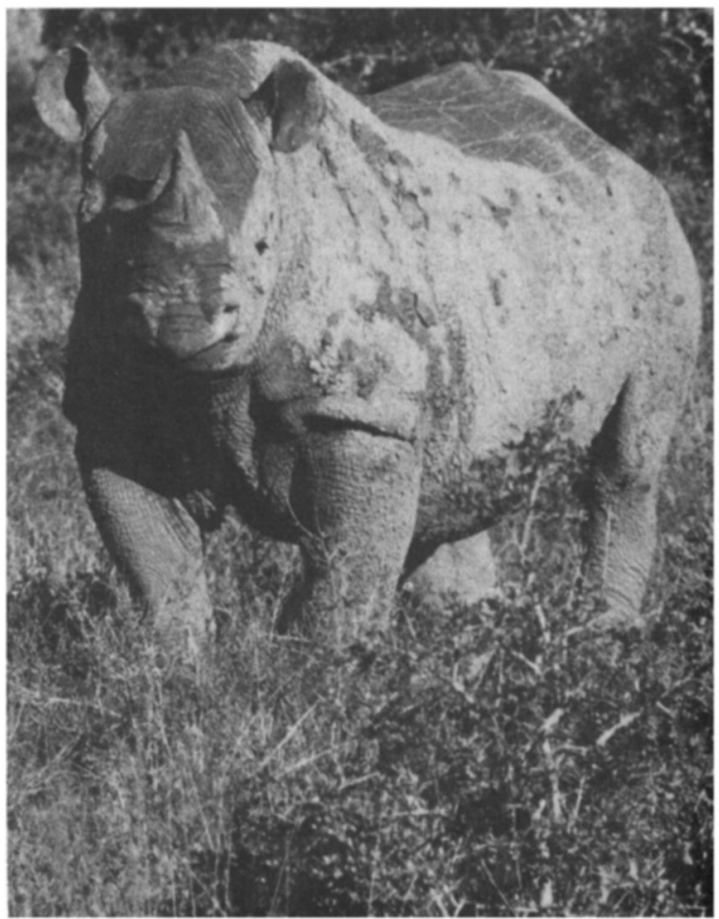

Black rhino (A. Hall-Martin).

detailed population surveys, an assessment of prospects and management costs, an identification of the most important herds that can be protected by improved surveillance in their natural state, and plans to consolidate the remnant, vulnerable herds into a few safe locations (Western, 1984). It may be periodically necessary to exchange individuals between small populations and from overpopulated sanctuaries to safe rehabilitation sites in order to avoid inbreeding. If and when rhino hom demand falls to safe levels, animals can be rehabilitated to former parts of their range, as has been done successfully in many areas in their southem range (HallMartin, 1979).

The only hope of reducing demand for rhino hom to tolerable levels is for concerted international action in closing all remaining trade avenues. According to Martin (1983), North Yemen, Singapore, Taiwan, China and South Korea are the principal consumers or traders in rhino hom. Moreover, Hong Kong has kept up supplies to other Asian countries by virtue of a legal provision allowing it to re-export old registered stock. 
Martin also suggests that international lobbying is paying dividends in Asia, as evidenced by a static price over the last few years in the face of a more than 50 per cent fall in rhino hom supplies. The traditional pharmacists' increasing awareness of the precarious state of rhinos and their switch to cheaper substitutes, such as saiga antelope horn, is evidently responsible, a trend that should be promoted more forceably by international conservation bodies.

The AERSG has lobbied strongly for greater international attention to trade bans, and there are hopeful signs that such efforts are working. Singapore, for example, has recently announced that, in the near future, it will sign the Convention on International Trade in Endangered Species of Wild Fauna and Flora (CITES). Hong Kong's rhino horn stocks are down from $3000 \mathrm{~kg}$ in 1982 to $289 \mathrm{~kg}$, and no longer pose a significant legal loophole. North Yemen, despite a declared ban in response to intense lobbying by the African Wildlife Foundation, remains the single largest consumer, absorbing around 50 per cent of all African rhino horn, almost exclusively exported from Khartoum, a CITES signatory.

At the urging of the AERSG, the IUCN undertook at its 1984 Madrid General Assembly to promote an international lobby to close the remaining rhino horn trade outlets. If this can be done soon with the strong support of the relevant African states, rhinos in Africa may gain a sufficient reprieve for reinforced conservation programmes, especially in eastern Africa, to take hold and reverse their rapid extermination.

\section{Acknowledgments}

We thank the many people who responded to our questionnaire surveys, Kes Hillman for valuable discussions, and the New York Zoological Society for funding this study.

\section{References}

Anon. 1984. Rhinoceros in South and South West Africa Endangered Wildlife Trust's Rhino Workshop.

Borner, M. 1981. Black rhino disaster in Tanzania. Oryx, 16, 59-66.

Bryden, H.A. 1897. Nature and Sport in South Africa. Chapman and Hall Ltd, London.

Douglas-Hamilton, I. 1983. Elephants hit by arms race. African Elephant and Rhino Group Newsletter, 2, 11-13.

Goddard, J. 1967. Home range behaviour and recruitment rates of two Black Rhino populations. E. Afr. Wildl. J. 5, $133-150$.
Goodman, D. 1981. Demographic intervention for closely managed populations. In Conservation Biology (eds M. E. Soulé and B. A. Wilcox). Sinauer Association, Sunderland, Massachusetts.

Groves, C.P. 1967. Geographic Variations in the Black Rhinoceros Diceros bicomis. Sonderdruck aus z.f. Sangetierkunde Bd, 32, 267-276.

Grzimek, B. 1964. Rhinos Belong to Everybody. Collins, London.

Hall-Martin, A.J. 1979. Black rhinoceros in southern Africa. Oryx, 15, 27-32.

Hillman, K. 1980. Rhinos in Africa now. Swara, 3, 22-24.

Hillman, K. 1981. The Status of Rhino in Africa and an Action Programme. IUCN/WWF/NYZS Africa Rhino Group Report.

Hillman, K. 1983. The Status of Northern White Rhinos. African Elephant and Rhino Group Newsletter, 1, 5-7.

Hillman, K., Mankoto Ma Oyisenzoo and Smith, F. in press. A last chance to save the northern white rhino?

IUCN. 1982. Elephants and Rhinos in Africa. A Time for Decision. IUCN, Gland, Switzerland.

Mackie, C. 1984. IUCN Project Underway in Garamba, Zaire. Pachyderm, Newsletter of the African Elephant and Rhino Specialist Group, No. 4, 17.

Martin, E.B. 1979. The International Trade in Rhinoceros Products. WWF Year Book 1979-80, 75-81.

Martin, E.B. 1983. Rhino Exploitation. WWF Hong Kong.

Owen-Smith, R.N. 1981. The white rhino overpopulation problem and a proposed solution. In Problems in Management of Locally Abundant Wild Mammals (Eds P.A. Jewell and D. Holt). Academic Press, London.

Parker, I.S.C. and Martin, E.B. 1979. Trade in African rhino horn. Oryx, 15, 153-158.

Ritchie, A.T.A. 1963. The Black Rhinoceros (Diceros bicomis L.). E. Afr. Wildl. J. 1,54-62.

Ruggiero, R.G. 1984. Central African Republic Hit by Poachers. Pachyderm, Newsletter of the African Elephant and Rhino Specialist Group 4, 12-13.

Sidney, J. 1965. The past and present distribution of some African ungulates. Trans Zool. Soc. Lond. 30, 61-87.

Simon, N. 1962. The status of species: Black Rhinoceros. In Between the Sunlight and the Thunder, pp. 254-258. Collins, London and Glasgow.

Soulé, M.E. 1981. Thresholds for survival: maintaining fitness and evolutionary potential. In Conservation Biology (Eds M.E. Soulé and B.A. Wilcox) Sinauer Association, Sunderland, Massachusetts.

Western, D. 1982. Patterns of depletion in a Kenya rhino population and the conservation implications. Biol. Cons. 24, 147-156.

Western, D. 1984. Humpty Dumpty and the Rhinos. African Elephant and Rhino Group Newsletter, 3, 4-5.

Western, D. and Sindiyo, D.M. 1972. The status of the Amboseli rhino population. E. Afr. Wildl. J. 10, 43-57.

David Western, Wildlife Conservation International, PO Box 48177, Nairobi, Kenya.

Lucy Vigne, Wildlife Conservation International, PO Box 48177, Nairobi, Kenya. 